A fine needle on a syringe was introduced through the cyst wall, and air under pressure pushed the syringe barrel outwards. At this point the surgeon and the anaesthetist realised that this pharyngocele had resulted from the inflated cuff of the laryngeal mask used. It was more prominent through the head having been turned to the opposite side. The "diagnostic" puncture of the cuff resulted in a slow deflation, which eventually necessitated the replacement of the mask owing to the development of laryngeal spasm. The surgeon was relieved of the need for further investigation of the swelling.

M HARDINGHAM

M M HILLS

Gloucestershire Royal Hospital

Gloucester GL1 3NN

1 O'Meara ME, Jones JG. The laryngeal mask. BMf 1993;306: 224-5. (23 January.)

EDITOR, - I am much less enthusiastic about the wholesale introduction of the laryngeal mask in this country than Moira E O'Meara and J Gareth Jones. ${ }^{1}$ An anaesthetist's ability to maintain airway patency by using a conventional facemask is not a skill easily acquired, nor is it made redundant by this new piece of equipment. There are circumstances-and I include cases of upper airway obstruction, epiglottitis being an obvious example -when such expertise is crucial to successful management.

There is a real danger that trainees who in their early years depend too much on the laryngeal mask will find themselves insufficiently experienced in this vital aptitude. It behoves those responsible for training junior anaesthetists to postpone any introduction to this novel device until the good old standby of bag and mask anaesthesia has been mastered.

Edith Cavell Hospital,

Peterborough PE3 6GZ

1 O'Meara ME, Jones JG. The laryngeal mask. BMF 1993;306: 224-5. (23 January.)

\section{Gestational diabetes mellitus}

EDITOR,-I am concerned about some of the analyses in Professor Jarrett's review of gestational diabetes.' A lack of consensus about terminology and definitions hampers progress, but does not imply that a problem is non-existent. He omits the work of the Diabetes Pregnancy Study Group of the European Association for the Study of Diabetes. This group has carried out a large multicentre study on glucose tolerance in normal pregnancy. ${ }^{2}$ It showed that more than $10 \%$ of normal pregnant women had two hour glucose concentrations after a $75 \mathrm{~g}$ glucose tolerance test of more than $8 \mathrm{mmol} / \mathrm{l}$ and were thus labelled as having impaired glucose tolerance. Pregnancy is clearly having an effect on glucose tolerance, a fact Jarrett dismisses. Indeed, in one longitudinal study in normal women, significant metabolic differences could be found over only one month in the third trimester. ${ }^{3}$ In view of the changes in glucose tolerance in pregnancy Lind $^{2}$ has recommended that for a $75 \mathrm{~g}$ glucose tolerance test the two hour cut off should be $9 \mathrm{mmol} / \mathrm{l}$ and for the one hour test, $10.5 \mathrm{mmol} / \mathrm{l}$. He further recommends the use of the term gestational impaired glucose tolerance for those women whose two hour value lies between 9 and 11 $\mathrm{mmol} / \mathrm{l}$, reserving the term gestational diabetes for those women who have a result indicating diabetes on a glucose tolerance test in pregnancy.

Jarrett dismisses excessive birth weight as being secondary to maternal obesity rather than glucose tolerance abnormalities. Although obesity seems to be the major factor, he fails to cite studies showing that glucose tolerance remains a significant factor even after allowance for maternal obesity. 4

Jarrett ignores studies that have investigated perinatal morbidity in association with abnormal results on a glucose tolerance test. In a study of over 200 women with abnormal results, each woman was compared with a control matched for obesity, age, ethnicity, and parity and who had screened negative for glucose intolerance. ${ }^{6}$ Results showed that stays on the neonatal care unit of more than 48 hours (brief admissions because of the labe diabetes were excluded) were significantly more common in those with abnormal results. Furthermore, with worsening glucose abnormalities the neonatal morbidity in terms of hypoglycaemia and polycythaemia was increased. Maternal obesity was not a significant factor.

Jarrett finishes by recommending that screening for abnormalities of glucose tolerance in pregnancy be discontinued. Even if one ignores any effects on the fetus and neonate, what about the mother? The longest follow up reported is by O'Sullivan. Reviewing women at between 22-28 years after the index pregnancy (when they had had abnormal glucose tolerance, but reverted to normal tolerance afterwards), he found a $50 \%$ prevalence of diabetes and $25 \%$ of abnormal glucose tolerance, whereas the controls had rates of $7 \%$ and $3 \%$. The stress of pregnancy on the maternal pancreas provides a most powerful predictor of the subsequent development of impaired glucose tolerance and diabetes. Thus women with a high probability of developing such problems can be separated out for preventive therapy research programmes, in an effort to decrease the morbidity and mortality these women subsequently suffer.

St Mary's Hospital for Women and Children,

MICHAEL MARESH Manchester M13 0JH

1 Jarrett RJ. Gestational diabetes mellitus: a non-entity? $B M \mathcal{J}$ 1993;306:37-8. (2 January.)

2 Lind TA. Prospective multicentre study to determine the influence of pregnancy upon the $75 \mathrm{~g}$ oral glucose tolerance test (OGTT). In: Sutherland HW, Stowers JM, Pearson DWM, eds. Carbohydrate metabolism in pregnancy and the newbom. Heidelberg: Springer-Verlag, 1989:209-26.

3 Maresh M, Gillmer MDG, Beard RW, Alderson C, Bloxham B, Elkeles RS. The effect of diet and insulin on metabolic profiles of women with gestational diabetes mellitus. Diabetes 1985.34 of women with

4 O'Sullivan JB, Gellis SS, Dandrow RV, Tenney BO. The potential diabetic and her treatment in pregnancy. Obstet Gynecol 1966;27:683-9.

5 Freinkel N, Metzger BE, Phelps RL, Dooley SL, Ogata ES, Radvany RM, Belton A. Gestational diabetes mellitus. Radvany RM, Belton A.
Diabetes 1985;34(suppl 2):1-7.

6 Maresh M, Beard RW, Bray CS, Elkeles RS, Wadsworth J. Factors predisposing to and outcome of gestational diabetes. Obstet Gynecol 1989;74:342-6.

7 O'Sullivan JB. Subsequent morbidity among gestational diabetic women. In: Sutherland HW, Stowers JM, eds. Carbohydrate metabolism in pregnancy and the newborn. Edinburgh: Churchil Livingstone, 1984:174-80.

EDITOR, - R J Jarrett has put forward the epidemiologist's view of gestational diabetes, pointing out the lack of a clear definition, the lack of consensus on treatment, and evidence suggesting that maternal glycaemia is not important in determining fetal size.' All of these points are well taken. Nevertheless, most clinicians would not view a mother with impaired glucose tolerance in pregnancy with the same sangfroid as epidemiologists, who view the data from afar. Why the discrepant views?

We recently retrospectively reviewed the data on mothers who had mild degrees of impaired glucose tolerance at Central Middlesex Hospital. It is policy to screen all mothers with risk factors for gestational diabetes (family history of diabetes, previous gestational diabetes, poor obstetric history, clinical polyhydramnios, maternal obesity, or previous macrosomic infant $(>4000 \mathrm{~g})$ with a $75 \mathrm{~g}$ oral glucose tolerance test at 30 weeks' gestation. In 260 pregnancies $(3.7 \%$ of the total) the two hour glucose value on testing was $>6.9 \mathrm{mmol} / \mathrm{l}$, and clinical details of the mother and baby were obtained from the case notes in these cases. Of relevance to the present argument were the correlations with the babies' birth size.

On regression analysis with birth weight as the dependent variable and maternal body mass curve, maternal weight gain during pregnancy, maternal age, and area under the glucose curve as independent variables, only maternal body mass curve reached significance as a factor predicting birth weight. This is in keeping with the findings of others. ${ }^{2}{ }^{3}$ It was apparent, however, that babies of mothers of Asian Indian origin were smaller than those of the other ethnic groups. Therefore, the babies' body mass curve was calculated in the same manner as for adults, from birth length and birth weight, and this measure was substituted for birth weight in the regression equation. In this model both maternal body mass curve and the area under the glucose curve emerged as significant factors in predicting body mass curve at birth $\left(r^{2}=10.5\right.$, $t=3.2$ and 3.1 respectively, $\mathrm{p}<0.01$ for both).

Birth length is notoriously difficult to measure. Nevertheless, we have attempted to derive a better index of fetal adiposity than simple birth weight and have found it to have a significant bearing on results of regression analysis, suggesting that maternal glycaemia does have an impact on fetal size independent of maternal weight.

Though macrosomia cannot be directly equated with morbidity, as long as maternal glycaemia during pregnancy can be shown to influence any aspect of fetal outcome the entity of gestational diabetes cannot be dismissed out of hand. We believe that screening programmes are still necessary to learn more about the condition. With the current interest in fetal nutrition and its influence on health in later life, now is not the time to be turning our backs on this important issue.

P S SHARP

R O'CONNOR

Northwick Park Hospital

Northwick

Middlesex HA1 3UJ

$S$ MCHARDY YOUNG J WOOTTON P FROST

Central Middlesex Hospital,

London NW10

1 Jarrett RJ. Gestational diabetes: a non-entity? $B M \mathcal{X}$ 1993;306: 37-8. (2 January.)

O'Sullivan JB, Gelliss SS, Tenney BO. Gestational blood glucose levels in normal and potentially diabetic women related to the birth weight of their infants. Diabetes 1966;15:466-70.

3 Green JR, Schumacher LB, Pawson IG, Partridge JC, Kretchmer $\mathrm{N}$. Influence of maternal body habitus and glucose tolerance on birth weight. Obstet Gynecol 1991;78:235-40.

EDITOR, - R J Jarrett documents the case against screening for diabetes in pregnancy. ${ }^{1}$ As studies have focused on the immediate pregnancy related complications of gestational diabetes it is not surprising that the value of such screening has not been properly investigated as far as long term complications are concerned. In the long term, the offspring may develop diabetes and the woman may suffer from progression of the disease to complications such as diabetic nephropathy and renal failure.

Evidence on the value of screening has been obtained mostly from countries with well developed health care systems. The prevailing conditions in other settings may be quite different: higher levels of perinatal morbidity and mortality as well as poor access to antenatal care and other health services. Therefore, it is inadvisable to extrapolate from those studies to disadvantaged populations. Furthermore, disadvantaged groups, both within our society ${ }^{2}$ and in developing countries, ${ }^{3}$ have been shown to be at high risk from gestational diabetes.

In the current economic climate it is not justi- 
fiable to provide screening services of doubtful value. But it is imperative to ensure that research is carried out on the value of screening for gestational diabetes in those hitherto neglected settings. We shall then be in a much better position to state when and where screening does more good than harm.

LINDSAY EDOUARD ROLAND F DYCK

College of Medicine,

University of Saskatchewan,

Saskatoon,

Saskatchewan,

Canada S7N 0W0

1 Jarrett RJ. Gestational diabetes: a non-entity? BMF 1993;306: 37-8. (2 January.)

2 Dyck RF. To screen or not to screen? Can Med Assoc $\mathcal{f}$ 1993;148:12.

3 Zimmet PZ. Challenges in diabetes epidemiology - from West to the rest. Diabetes Care 1992;15:232-52.

\section{Alternative allergy and the GMC}

EDITOR,-It is disingenuous of Robert Kilpatrick to claim that the General Medical Council was not created "to protect the public against quacks." The objective defined in 1858 was to enable "persons requiring medical aid ... to distinguish qualified from unqualified practitioners" and we need only read some early issues of the Lancet to learn that the medical register was regarded at the time as a list of doctors who set themselves higher standards than the multitude of quacks who then preyed on the sick.

From the beginning, the register sought to record the names of doctors whose education and behaviour conformed to standards of which the GMC approved. It may soon, thanks to the reforming energy of its president, be able to demand that registered doctors conform to standards of competence and performance laid down by the council. As a patient, I would like to think that the presence of a doctor's name on the list would also offer me some sort of guarantee that he or she would not subject me to unnecessary or unjustifiably harmful treatment-whether that treatment be labelled alternative or mainstream, labels that serve only to confuse the issue. My definition of harmful treatment would embrace not just treatment that exposed me to risk without any hope of compensating benefit but treatment of unproved efficacy that diverted me from having other treatments that were of proved value.

To satisfy that humble demand the GMC, pace its president, would not have to set itself up as "an investigation bureau to assess the scientific validity of new treatments before allowing doctors to use them." It need only do what it does now when it examines doctors' behaviour by asking them to justify that behaviour before a panel of their professional peers. That surely is the principle of self regulation, and its justification.

I find it sad that the business of getting practitioners, medical or alternative, to provide evidence of the efficacy of the treatments they use is left largely to consumer organisations, and to a financially hard pressed charity like HealthWatch, which has to step in where the professionals seem afraid to tread.

It is irrelevant to argue, as Robert Kilpatrick does, that the GMC has no power of regulation over unqualified practitioners. If people want to prescribe unproved forms of treatment, or to receive them, that is their choice. All that some of us ask is that "GMC attested" doctors should be prepared to justify the treatments they use with evidence that is acceptable to their peers. If they don't want to do that they can still practise as unregistered practitioners, using an adjective that might offer their clients the same frisson as "alternative."
To say that the GMC should not get involved in assessing the acceptability of a treatment a docto uses in the way it is now prepared to assess a doctor's professional behaviour is to cede the argument to those who claim that self regulation has become an introspective, bureaucratic activity that has grown detached from its original purpose of protecting patients.

Godalming,

MICHAEL O'DONNELL

Surrey GU8 4BD

1 Kilpatrick R. Alternative allergy and the GMC. BMF 1993;306: 328. (30 January.)

2 Garrow J. Alternative allergy and the GMC. BMF 1993;306:329. (30 January.)

EDITOR,-The alleged beliefs and practices of clinical ecology portrayed by A B Kay' bear only a superficial and pejorative resemblance to the actual published positions of the field's representative organisation, the American Academy of Environmental Medicine, known as the Society For Clinical Ecology until 1985. Responsible leaders in this field have dubbed Kay's artificial entity the "straw man of clinical ecology." It was created by sewing together carefully chosen bits and pieces of abstractions from various articles culled from the field's diverse literature. It is a pejorative conglomeration of selected perceptions that characterises the field and its practitioners as bizarre, irresponsible, and unscientific, lacking any reason to give them any credibility. Various threatened vested interests seem to have designed this portrayal specifically to discourage any honest, in depth inquiry into the actual tenets of the field.

The actual official published positions of the field provide a new and powerful model of environmental medicine that contains numerous valuable insights and perspectives into the dynamic causes of many acute and chronic illnesses and provide powerful tools to vastly improve both the quality and cost effectiveness of the health care of applicable illnesses.

A B Kay is entirely correct when advocating that the medical establishment is obligated to take action that is in the best interest of the general public. This interest can best be served by all responsible members of the scientific community beginning and sustaining an objective, scientific, honourable, and openminded face to face dialogue based on the actual and official tenets of clinical ecology/environmental medicine.

For the opening steps in this dialogue, interested readers are urged to obtain the official and responsible positions of the field as outlined in four documents: the official philosophy paper $^{2}$ and practice guidelines ${ }^{3}$ of the American Academy of Environmental Medicine; the official bibliography of the founder of the field, Theron G Randolph, $\mathrm{MD}^{3}$; and Chemical Sensitivity: Volume $1,{ }^{4}$ the first volume of a four volume work that is destined to become the magnum opus on the topic of chemical sensitivity, which is an important component of the larger discipline.

American Academy of Environmental Medicine, GARY R OBERG

PO Box 16106,

Denver, $\mathrm{CO} 80216$

USA

1 Kay AB. Alternative allergy and the General Medical Council. BMF 1993;306:122-4. (9 January.)

2 Oberg GR. An overview of the philosophy of the American Academy of Environmental Medicine. Denver: American Academy Medicine, 1992. (Obtainable for $\$ 5.00$ from the AAEM.)

3 American Academy of Environmental Medicine. Practice guidelines. Denver: AAEM. (Free copies available from the American Academy of Environmental Medicine.)

4 Randolph TG. Environmental medicine-beginnings and biblio graphies of clinical ecology. Fort Collins, Colorado: Dickey Eraphies of clinical

5 Rea WJ. Chemical sensitivity: volume 1. Boca Raton, FL: CRC Press, 1992.
EDIroR, - There have basically been two criticisms of my article' and Richard Smith's editorial' ${ }^{2}$ on alternative allergy and the General Medical Council (GMC)-firstly, that it is not the GMC's job to censor alternative practitioners and, secondly, that the neutralisation-provocation technique has in fact been validated. ${ }^{3}$ Both points deserve comment.

In 1989 the Medical Practitioners Disciplinary Committee of New Zealand found Dr D W Steeper guilty of professional misconduct for his use of the Vega testing machine in diagnosing allergy. ${ }^{4} \mathrm{Un}$ orthodox or alternative medicine was not on trial. The committee, however, did not accept that $\mathrm{Dr}$ Steeper had adopted any "theory of medicine or surgery" in the use to which he put his machine. Since he was practising alternative medicine under the guise of orthodox medicine the committee believed that he had misled his patients and that this amounted to professional misconduct. Part of the disciplinary action taken was to ensure that patients were made aware when he employed alternative medical practices and that written consent was obtained in advance. Perhaps the GMC could consider a similar requirement.

The question of validity of the methods of clinical ecologists is essentially what constitutes good science. Good science involves collegiality and consensus and the long and arduous process of replication and verification. Pivotal to medical scientific progress is the scientific literature, with the discipline imposed by writing and the reasoned critical argument in which the strengths and weaknesses of the scientific case are stated. If published claims are of any real importance others will want to repeat, verify, contradict, or confirm them. Papers written by clinical ecologists for clinical ecologists in clinical ecology journals have little scientific impact. In fact, neither Clinical Ecology nor the fournal of Nutritional Medicine is even mentioned in the Science Citation Index fournal Citation Reports.

A report by the Royal College of Physicians of London concluded that studies of clinical ecologists were seriously flawed. ${ }^{5}$ More serious is the fact that conventional doctors do not accept that there is such a thing as "environmental illness" or the "total allergy syndrome." They find the definition ("a polysymptomatic disorder . . . caused by environmental excitants")absurd, not least because it fails to exclude other polysymptomatic diseases -that is, psychiatric illness.

A B KAY

Department of Allergy and Clinical Immunology, National Heart and Lung Institute, London SW36 6 Y

1 Kay AB. Alternative allergy and the General Medical Council. $B M F$ 1993;306:122-4. (9 January.)

2 Smith R. GMC in the dock again. BMF 1993;306:82. (9 January.) 3 Correspondence. Alternative allergy and the GMC. BMF 1993; 306:328-31. (30 January.)

4 Medical Practitioners Disciplinary Committee. Professional misconduct findings against Dr D W Steeper. NZ Med $\mathcal{J}$ 1990;103:194-5.

5 Royal College of Physicians of London. Allergy. Conventional and altemative concepts. London: RCP, 1992.

\section{Sexual behaviour}

EDITOR,-Colin Francome ${ }^{1}$ repeats an assertion made by Gurman ${ }^{2}$ and others. We agree that in broad terms the mean number of heterosexual partners reported by men must be equal to the mean number reported by women over a specified time interval in a closed population. In datasets from different countries men consistently report more partners than women, and the British data show smaller differences than many others $(T W$ Smith, paper presented to American Sociological Association, Cincinnati, 1991).

Several reasons have been proposed to explain some of this discrepancy. ${ }^{3}$ The mean is an unstable statistic influenced by a small proportion of the population with large numbers of partners; 